\title{
The Use of Avatars in Gender Segregated Online Learning Within MOOCs in Saudi Arabia - A Rwaq Case Study
}

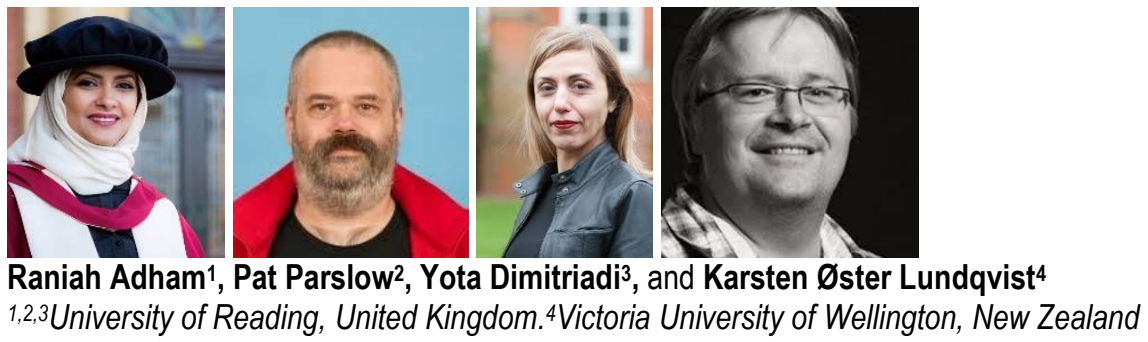

\begin{abstract}
In Saudi Arabia, gender-segregation is a known issue within higher education that often deprives female tutors from providing online learning and Massive Open Online Courses (MOOCs). As well, students may not be getting the benefit of their experience and teaching. The purpose of this study is to develop an Avatar tool to represent a female tutor in a MOOC course with the aim of alleviating the issues of a gender-segregated society in online learning. This project will undertake and analyse a case study concerning the experience of females teaching a MOOC course on "Rwaq" the first Saudi Arabian platform, which was launched in September 2013. The literature on gender-segregation and education technology is reviewed. As an example, gender-segregated in higher education and online learning in Saudi Arabia, Virtual Learning Environments (VLE), Avatar technology in higher education, and finally the adoption of an Avatar tool in MOOCs platforms in SA are examined. One of the objectives of the study is to develop a social interaction environment with learners in online learning within MOOCs. The ultimate objective of this study is to examine if this Avatar tool could alleviate issues of gendersegregation for female lecturers in online learning courses within MOOCs in higher education in Saudi Arabia.
\end{abstract}

Keywords: online learning, MOOCs, Avatar, Rwaq, Saudi Arabia 


\section{Introduction}

This paper is a continuation to the work the researchers have addressed in previous published proceedings (Adham, Lundqvit, \& Parslow 2016). In 2012, MOOCs had a major revolution in the Western world and in 2013, MOOCs started to appear in a few countries in the Middle East. They are continuing to progress into a more widespread form of educational technology (Adham \& Lundqvist, 2015; Subbian, 2013; Liyanagunawardena, Adams, \& Williams, 2013). MOOCs as online courses are free courses, offered to a large number of learners at once, and conducted via video lectures and online assignments and exams (Universities UK, 2013). However, the overload of sources, educational knowledge, and economic, social, and cultural aspects of MOOCs might be considered a huge challenge for learners from developing countries (Liyanagunawardena, Williams, \& Adams, 2013).

The recent situation in the Middle East presents some challenges regarding the impact of eLearning on social and cultural factors in higher education (HE), and these could restrict the progress of education. Gender for instance, has been found in some studies to be a very influential factor in terms of using Elearning; indeed, gender plays a significant role in how students engage with online courses (Garland \& Martin, 2005). Moreover, males and females could possibly react in a different way to the material, methods presented, participation, and interaction with the tutor (Gulati, 2008).

The Kingdom of Saudi Arabia considered to be the keeper of the Islamic religion and one of the most conservative Muslim countries in the world, especially in regard to the status of women (Baki, 2004). The Saudi Arabian society is unlikely to support gendered-segregation due to its religious and cultural restrictions (Onsman, 2011). Moreover, in Saudi Arabia, the obligatory gender-segregation by religious, social, and cultural traditions has heavily impacted on the achievement of women in the higher education institutions, therefore; online learning might be good idea to remove such barriers (Baki, 2004). In Saudi universities, the adaptation of online education methods in the university culture; is considered a big issue in the development of E-learning system (Graham, Allen, \& Ure, 2005). Overall, Saudi Arabia is facing the challenge of achieving international credits and competitive borders in higher education, while maintaining the traditional cultural standards.

\section{Literature Review}

Virtual World (VW) can be considered one of the key methods of producing E-learning platforms. It was developed from the three-dimensional worlds and engaging atmosphere of video games (Messinger et al., 2009). Moreover, VW motivate students, as they can be challenging and enjoyable, enhancing imaginary and social perception. They frequently influence students who do not do well in the traditional way of learning (Dede, 2004).

Virtual Learning Environments (VLEs) is the need of a worldwide learning experience and the learners' interface together might help to discover some upcoming directions by using widespread Internet software such as Second Life (SL; Christensen, Horn, \& Johnson, 2008). In the 1990s, Avatar technology was first introduced, however, there were several technical difficulties, for example the slow phases for interaction (Oestreicher, Kuzma, \& Yen, 2010). According to Fabri, Elzouki, and Moore (2007) the term Avatar is “(c) Comes from the Sanskrit language and can be translated as God's Incarnation on Earth" (p 275). As González, Santos, Vargas, Martín-Gutiérrez, \& Orihuela (2013) defined Avatar as the digital representation of the individuals within the virtual world. It has an ability 
to perform actions and to simulate human-to-human interactions to increase engagement and hence learning. Furthermore, Nowak and Rauh (2005) stated that the digital age users prefer to choose gender-compatible Avatars. The identity factors, for example, gender and age, have an effect on the use of Internet and perceptions of Avatars. It is possible that an Avatar can be viewed as a strong social indication affecting perceptions of computer users, motivating them to recognise interfaces as more social. Foundational research demonstrates how elements of the virtual world's environment, such as SL Avatars, can be used in education, potentially increasing social presence (Jamaludin, Ho, \& Chee, 2007). On the other hand, the use of VLEs and 3-D technology has been successfully implemented in higher education; nevertheless, it is still considered a new approach to teaching and learning in universities (Christensen et al., 2008). Then again, many well-known universities around the world, such as Harvard, Stanford, and the Open University have been using Second Life as a motivating part of their learning and teaching systems. Furthermore, benefits deriving from the application of Avatars in teaching include offering opportunities for social interaction and community development, dissolving social restrictions, reducing social anxiety, and enhancing learners' motivation (Hamalainen, 2008). In a 2009 interview, Dyson stated that "The Avatar technology may present lectures and seminars to a real lecture presented in a lecture theatre" (Oestreicher et al., 2010, p.4).

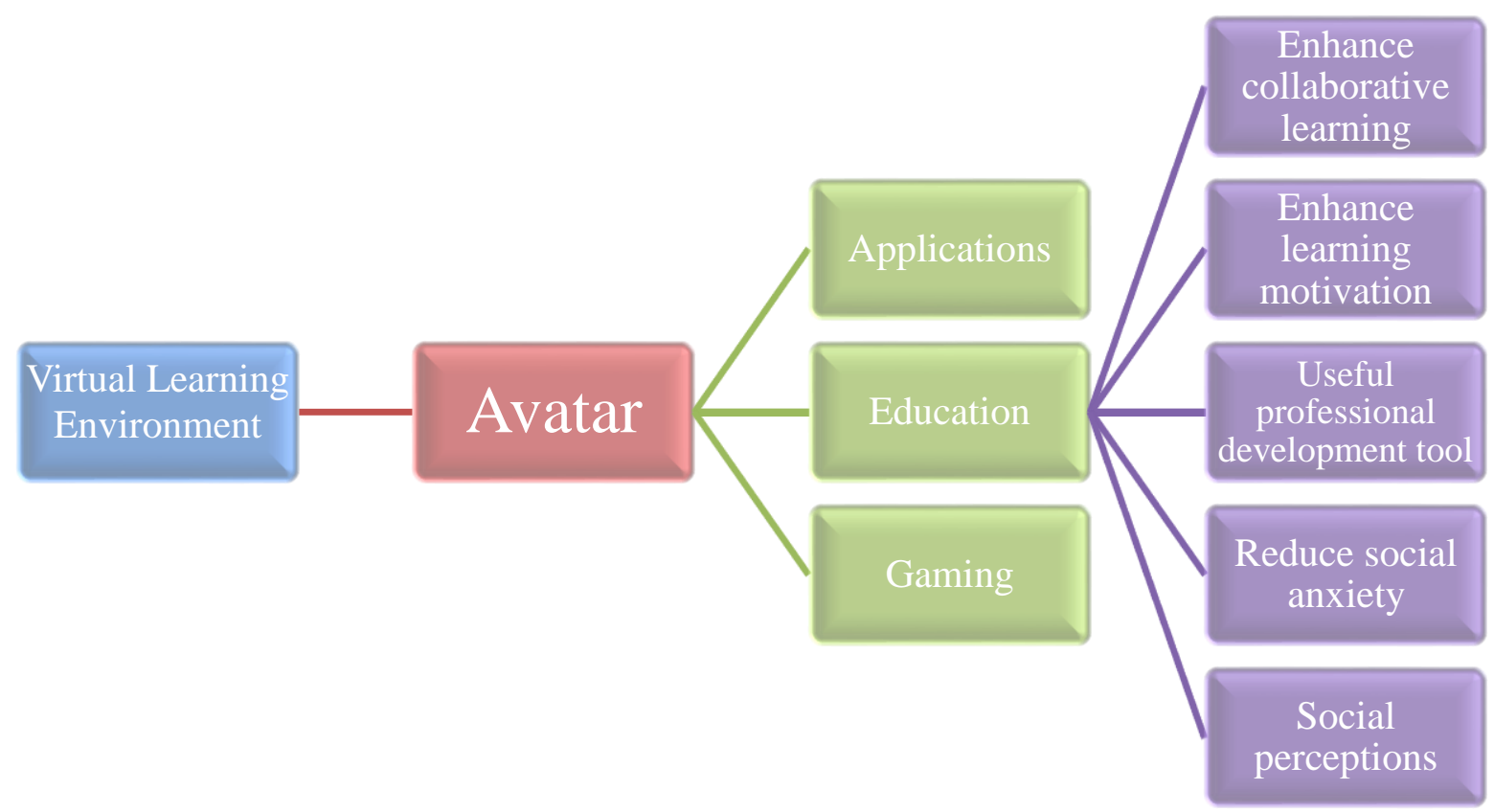

Figure 1. The Avatar technology.

\section{Adopting the Avatar Technology in Saudi Arabian MOOCs}

The Avatar technology might become an attractive method in teaching; however, results need to have good standards for teachers and learners (Oestreicher et al., 2010). In Saudi Arabia, one can come across certain limitations on online teaching for instance, not all students' locations can provide good Internet connections to allow quick interactions. Another limitation is the language barriers and the issue of gender-segregation, where the majority of female academics don't choose to appear physically within online courses. For example, Rwaq's statistics showed that during the years 2015 and 2016 a total of 125 courses were run, however only 25 were led by female teachers. 


\section{Research Questions}

1. To what extent can the role of Avatars enhance teachers' and learners' motivation in online learning and MOOCs in SA?

2. Can the use of Avatars in online courses impact/address issues of gender-segregation in SA?

\section{Methodology}

This research is ethnographic-action research; accompanying action research, ethnographic research can provide the tools and techniques. Recently, technology researchers have started to use the ethnographic research method to view the implementation of technologies within social systems (Hartmann, Fischer, \& Haymaker, 2009).

It was decided within this research to adopt a mixed-methods approach to provide appropriate answers to all posed questions, and to draw on the strengths and minimize the weaknesses of the research. It is an exploratory case study, which is used widely in educational research (Yin, 2009). The case study approach focuses on adopting a new teaching method using Avatars in MOOCs to aid the exploration of this new technology by female tutors in teaching and learning. It is done to alleviate social and cultural issues so that female tutors can interact socially with learners in online course within MOOCs in SA. The case study has been structured upon consideration of two main pedagogical approaches - social constructivism and collaborative learning (associated with gender) - in order to provide a new perspective on technology enhanced learning with the aim to enable the use of these pedagogical theories. In this study, the data is collected by the researcher's online teaching experience as well as the cultural meaning of the participants' story using an auto-ethnography approach (Creswell, 2017). At the end of the course, an electronic survey using Google Forms was sent by the instructor (the researcher) to Rwaq participants' emails. The official communication required to obtain the permissions and ethical approval from University of Reading for conducting the study has already been carried out.

\section{Data Analysis}

The data analysis for this study consisted of both quantitative and qualitative methods, since there were three components of the data collection: the researcher's online teaching experience, the participants' perceptions, and the end of course (satisfaction) survey, as explained in this paper. The first component is the phenomenological analysis of qualitative data drawn from the teacher's online experience, whereby it was revealed how individuals make sense of a particular phenomenon (Savin-Baden \& Major, 2013). This approach is generally centred on actual life experience, which is then narrated as a story, thus providing a general description of the experience. In this case, important elements are presented; for example, social interaction (teacher-to-student and student-to-student), feedback, assessment, challenges, and what the majority of the learners expect from their teacher.

The second component is the participants' feedback, which was analysed thematically. Thematic analysis is a "systematic approach to identify, analyse, and report patterns within data and interpreting it by seeking commonalities, relationships, or explanatory principles" (Braun \& Clarke, 2006). It is commonly used in many fields, including case study research due to its flexibility. The data were 
consequently coded into categories, according to information interpreted from the participants' feedback and comments.

The final component is the quantitative data analysis at the End of Course Survey. An electronic questionnaire was used, as this provide a rapid means of collecting information in an impartial way from participants (Stopher, 2012). The questionnaire was designed using Google Forms online software. Therefore, a link was sent to each Rwaq participant by e-mail through a disclaimer on the relevant platform. This facilitated the data collection and analysis. The validity and usability of such a system was thus evaluated; for example, its ease of use, ease of navigation, clarity of videos, and quality of sound. The quantitative data obtained were subsequently analysed using descriptive statistics and figures, which added depth to the questionnaire and triangulated the data obtained from the participants' perceptions and feedback.

\section{Software Analysis Tool}

A software analysis tool was used to assist with analysing the qualitative data gathered. NVivo version 11 is a Computer-Assisted Qualitative Data Analysis Software (CAQDAS) used in conjunction with a coding process applied to the data, whereby meaning is captured (Savin-Baden \& Major, 2013).

\section{The Participants}

The sample for this study was drawn from a Rwaq course and included 5580 participants, fairly distributed by gender ( $48 \%$ females, $52 \%$ males). The participants originated from different Arabicspeaking countries, held different levels of educational qualifications, and varied in age (see Table 1).

Table 1

Participants' Ages and Levels of Educational Qualification

\begin{tabular}{|c|c|c|c|}
\hline Degree & Total & Age range & No. of Participants \\
\hline \multirow{5}{*}{$\mathrm{PhD}$} & \multirow{5}{*}{436} & Under 20 & $\mathrm{o}$ \\
\hline & & $20-29$ & 4 \\
\hline & & $30-39$ & 207 \\
\hline & & $40-49$ & 171 \\
\hline & & Over 50 & 54 \\
\hline \multirow{6}{*}{ Master's degree } & \multirow{5}{*}{2349} & Under 20 & 4 \\
\hline & & $20-29$ & 931 \\
\hline & & $30-39$ & 948 \\
\hline & & $40-49$ & 344 \\
\hline & & Over 50 & 122 \\
\hline & & Under 20 & 78 \\
\hline
\end{tabular}




\begin{tabular}{|l|l|l|l|}
\hline \multirow{3}{*}{ Bachelor degree } & \multirow{2}{*}{1914} & $20-29$ & 864 \\
\hline & & $30-39$ & 724 \\
\hline \multirow{3}{*}{ Secondary Education } & \multirow{2}{*}{881} & $40-49$ & 198 \\
\hline & & Over 50 & 50 \\
\hline & & Under 20 & 174 \\
\hline & & $20-29$ & 376 \\
\hline & & $30-39$ & 104 \\
\hline & $40-49$ & 201 \\
\hline
\end{tabular}

\section{The Setting}

The setting for this study is a Meta-MOOC on a Rwaq platform, implementing the Avatar technology, "How to Design your own MOOC Course." This was developed over a four-week period from August $8^{\text {th }}$ to September $8^{\text {th }}$, 2016; using Go-animate software instead of videos of the presenter. The content and materials were then developed within two months and translated from English into Arabic, following Rwaq's language procedure (Rwaq, 2015). The Avatar and corresponding videos were consequently created, with added recordings of my own (the teacher/researcher's) own voice.

On May $15^{\text {th }}, 2016$ an online application was submitted to Rwaq, specifying the MOOC course title and outline. It was accepted with a request for a short introductory video of around two or three minutes' duration. Here, the teacher was able to introduce herself, give an outline of the course, and indicate the target audience. This "promo-video" was published on May $24^{\text {th }}, 2016$, in order to initiate its publication. It was also shared on social media networks, namely Twitter and Facebook-using the teacher's private accounts-as well as being disseminated via WhatsApp chat groups on mobile devices. On August $8^{\text {th }}$, 2016, the first MOOC course was launched on the Rwaq platform. This comprised four recorded lectures divided into 14 short videos, published on a weekly basis, it can be access via YouTube Rwaq Chanel (https://www.youtube.com/watch?v=-AVJh36L N8). The End of Course Survey was published in the third week. Finally, at the end of the course, a test was administered, with a $60 \%$ pass mark, whereby successful candidates received a certificate of completion from Rwaq. The Table 2 is the four weeks Rwaq course outline: 
Table 2

The Rwaq Course Outline

\begin{tabular}{|c|c|}
\hline & Course outline/objectives \\
\hline \multirow[t]{4}{*}{ Week 1} & Introduction to Massive Open Online Course MOOCs. \\
\hline & What is MOOCs? \\
\hline & The History and background of MOOCs. \\
\hline & How to create a content of a MOOC course. \\
\hline \multirow[t]{5}{*}{ Week 2} & Create a preview page. \\
\hline & Summary of the course and instructor profile. \\
\hline & Introduction video and welcome email. \\
\hline & How to participate in the open platforms as a teacher. \\
\hline & Create assessments (Multiple choice \& quizzes). \\
\hline \multirow[t]{4}{*}{ Week 3} & How to create the visual course content. \\
\hline & How to create an interactive video. \\
\hline & Style of your visual content. \\
\hline & How to create a video using an Avatar. \\
\hline \multirow[t]{4}{*}{ Week 4} & Online learning for Saudi females in higher education. \\
\hline & $\begin{array}{l}\text { Women opportunities for online teaching and their impact on Saudi } \\
\text { culture. }\end{array}$ \\
\hline & Arabic female role in online learning and MOOCs. \\
\hline & $\begin{array}{l}\text { Interview with female lecturers teaching experience on Rwaq (as part of the } \\
\text { study). }\end{array}$ \\
\hline
\end{tabular}




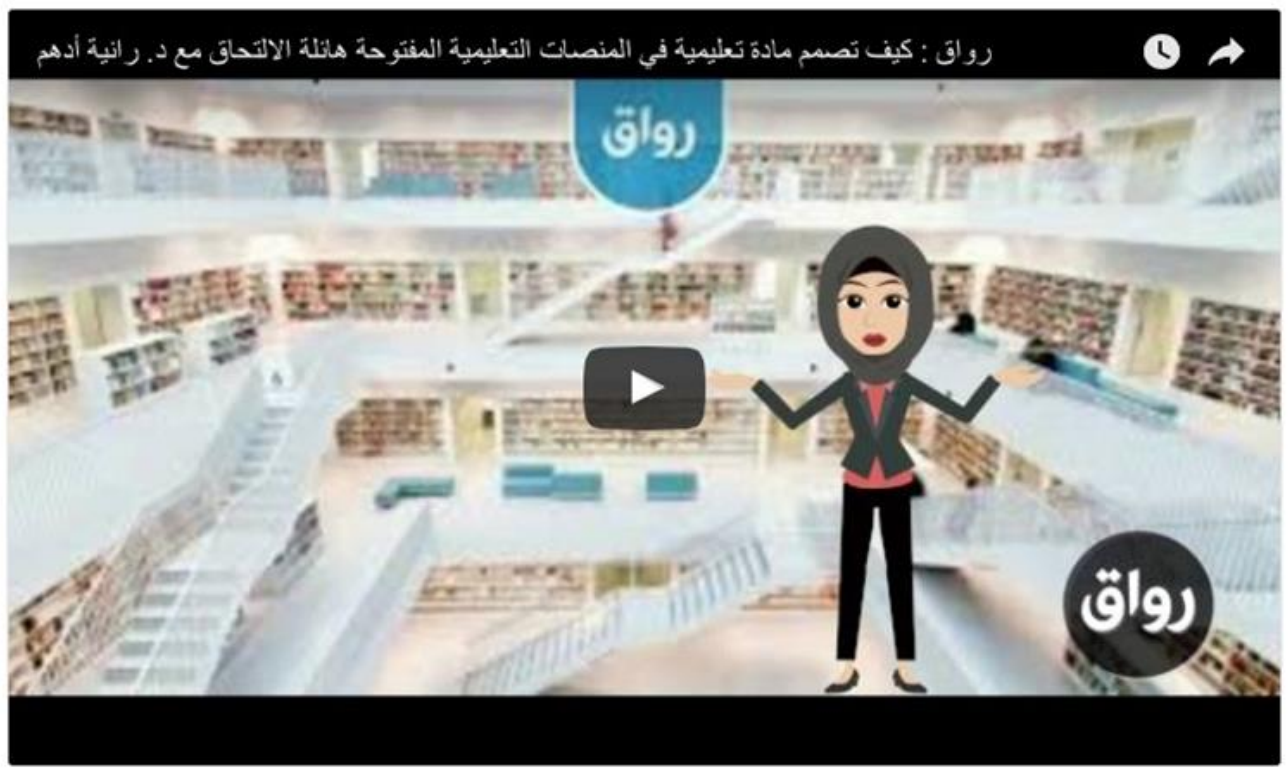

Figure 2. Screenshot of video on the Rwaq course.

\section{The Results}

The relevant statistics from my first Rwaq course are presented below:

- Out of a total of around 5,580 participants, $30 \%$ completed the course.

- A total of $23 \%$ of all participants successfully completed the final test.

- A total of $14 \%$ of all participants completed the End of Course Survey.

\section{The Researcher's Online Teaching Experience}

When the teacher (First author) decided to teach a MOOC course, she realised that it is needed to create a quality course for students. She also wanted to share the ideas underpinning the $\mathrm{PhD}$ research, in order to gather perceptions and suggestions that could be helpful and inspiring to other female teachers in future. She therefore endeavoured to estimate how long it would take to prepare an online course. It ultimately took around two months to develop all the course materials, create the Avatar videos, and design the final test and survey. It was therefore more time-consuming to prepare than a traditional classroom course.

When the first lecture was published on the Rwaq platform on August 8 $8^{\text {th }}$ 2016, a high number of comments were received from participants, posted under each video. This gave rise to some important questions. As a result, the teacher usually spent approximately three hours a day following participants' discussions on the messages, wall, and discussion boards, as well as regularly checking her own e-mail inbox. In this way, she attempted to respond to participants' questions and comments as promptly as she could, because it was considered very important for them to know that the teacher was consistently available to help them whenever required. As a result, an interactive online environment was established, where participants felt free to participate in discussions and respond to posted comments. This was intended to make them more comfortable about responding to each other on the discussion board. 
In addition to the above, she tried to keep everything simple, including the course content, while also avoiding long videos, or long and complex questions in the final test. This was intended to help achieve the learning goals. For example, the participants were sent a welcome letter before the commencement of the course and the syllabus was posted in advance; thus giving the participants an opportunity to familiarise themselves with the course as a whole, as well as to reflect on whether it would meet their needs. Moreover, some of the participants were highly motivated and had an intrinsic desire to use the course material in their learning. They therefore wanted to practice applying what they had learnt and enjoyed the process (intrinsic motivation). However, others may only have been seeking to complete the course as a means of obtaining the certificate (extrinsic motivation).

Aside from the above, this course was highly feedback-oriented in the research study; with the participants being made aware from the beginning that they were welcome to share their views on the course. Researchers generally have an opportunity to gather feedback from participants at the end of an online course, but my teaching experience in this MOOC course strongly suggests that feedback should be encouraged and reviewed throughout a course.

The online teaching experience provided me as a teacher with many benefits, as I had a window on most of the participants' discussion. I was consequently able to note and correct any misinformation, while also easily identifying those participants who required additional help. In my opinion, this was a key advantage, as I believe that a good online course is one where the teacher is present and supports the students. In addition, I learned a great deal from the participants about massive online open courses (MOOCs), new platforms, and updated animation tools and software. Furthermore, my primary goal was for the participants to be able to access and learn from material within a socio-interactive environment. The significance of this is heightened by the cultural and social boundaries imposed on female teachers in Saudi Arabia.

Most of the participants proved to be greatly interested in the Avatar videos and I observed this in their comments, which I will consider in more detail in the section on "Participants Perceptions and Feedback" (see below). The online teaching experience, with the new phenomenon of an Avatar tool being used to create videos, combined with recordings of the teacher's own voice, was thus explored from a female perspective. In this regard, both positive and negative aspects of online courses were encountered. Some of the advantages of teaching via a Meta-MOOC, using an Avatar as opposed to the physical representation of a presenter in videos involved the sense of being more fully engaged with the interactive education. Here, an appropriate Avatar character was created to closely resemble myself, as a female teacher. The aim was to be able to interact with the students and provide a memorable experience that would increase confidence, enhance satisfaction, and reduce social boundaries.

Conversely, one of the disadvantages of this new technology was the length of time and amount of effort required to create an Avatar in the first place; as well as learning how to navigate and communicate using the relevant software which took approximately two to three months to develop the 15 videos. Amongst other factors, I found that I felt more comfortable explaining things in writing, as opposed to orally. Sometimes, I also needed to find the necessary resources to answer the participants' questions. Another finding derived from teaching this course was that the participants were sometimes very interactive, but without much control. Furthermore, this interaction took place in multiple directions. 


\section{The Participants' Perceptions and Feedback}

The data collected related to the participants' feedback on the course content, material, Avatar tool, teacher-student interaction, and student-to-student interaction. Moreover, it pointed to ways in which these perceptions could impact their actions, approaches, and learning within the online educational environment. Besides, participants' feedback in the form of comments on course content is essential for the ongoing enhancement of course quality (Leckey \& Neill, 2001).

The data collected were subsequently subjected to a six-phase thematic analysis method, as described by (Braun \& Clarke, 2006), following their protocol for analysing qualitative data. The researcher analysed these themes in relation to the participants' responses to the course, coding them with NVivo software. The resulting five main themes are presented in the thematic map shown in (Table 3).

Table 3

Thematic Analysis of Participants' Responses

\begin{tabular}{|c|c|c|}
\hline Themes & Codes & $\begin{array}{l}\text { Excerpts from participants' } \\
\text { comments }\end{array}$ \\
\hline \multirow[t]{3}{*}{$\begin{array}{l}\text { 1. Students' perceptions: } \\
\text { Positive-Negative-Neutral. }\end{array}$} & Course & \multirow{3}{*}{$\begin{array}{l}\text { "It looks like it's a clear and } \\
\text { interesting course from the } \\
\text { beginning." } \\
\text { "I liked the presentation: very } \\
\text { attractive and beautiful." } \\
\text { "The Avatar is moving very quickly." } \\
\text { "Our... teacher programmed an } \\
\text { Avatar to act on her behalf... which } \\
\text { proved to be an effective method." }\end{array}$} \\
\hline & Videos & \\
\hline & Avatar tool & \\
\hline \multirow{2}{*}{$\begin{array}{l}\text { 2. Students' impressions: } \\
\text { Positive- Negative-Neutral. }\end{array}$} & Course content & \multirow{2}{*}{$\begin{array}{l}\text { "Wonderful and detailed explanation } \\
\text { of the background to MOOCs." } \\
\text { "One of the beautiful things in this } \\
\text { course is the short duration of the } \\
\text { videos and the organisation of } \\
\text { information in an interesting way." }\end{array}$} \\
\hline & $\begin{array}{l}\text { Organisation of the } \\
\text { course }\end{array}$ & \\
\hline \multirow[t]{5}{*}{$\begin{array}{l}\text { 3. Students' satisfaction with the } \\
\text { course. }\end{array}$} & $\begin{array}{l}\text { Types of material } \\
\text { (helpful/not helpful } \\
\text { information) }\end{array}$ & \multirow{5}{*}{$\begin{array}{l}\text { "Very interesting and important topic } \\
\text { in today's world, which depends on } \\
\text { electronic platforms in everything." } \\
\text { "I cannot download the } \\
\text { attachments." } \\
\text { "You motivated me a lot to design and } \\
\text { teach my educational materials as a } \\
\text { MOOC." } \\
\text { "Thank you very much and God bless } \\
\text { you." }\end{array}$} \\
\hline & Technical & \\
\hline & Teacher & \\
\hline & Platform & \\
\hline & Thanks & \\
\hline \multirow[t]{4}{*}{ 4. Questions and assessments. } & Requests & \multirow{4}{*}{$\begin{array}{l}\text { "I hope to continue to provide a series } \\
\text { of courses in the subject, taking into } \\
\text { account the practical side." } \\
\text { "What is the software you used in the } \\
\text { video?" }\end{array}$} \\
\hline & Enquiries & \\
\hline & Final test & \\
\hline & Certificate & \\
\hline
\end{tabular}




\begin{tabular}{|l|l|l|}
\hline 5. Social interaction. & $\begin{array}{l}\text { "What date is the exam?" } \\
\text { "How can we receive the certificate?" }\end{array}$ \\
\cline { 2 - 3 } & $\begin{array}{l}\text { Teacher-to-student } \\
\text { (discussion) } \\
\text { (passive learning } \\
\text { through others, } \\
\text { interaction with other } \\
\text { students via } \\
\text { comments) }\end{array}$ & $\begin{array}{l}\text { "The most fantastic subjects, infused } \\
\text { with passion for one's work and } \\
\text { scientific development." } \\
\text { "I hope that your research results } \\
\text { contribute to the promotion of Arab } \\
\text { women, in sharing what you have } \\
\text { learned and knowledge through } \\
\text { distance education." } \\
\text { "I am very happy to have participated } \\
\text { in this course and admire the style } \\
\text { and teacher's method of } \\
\text { explanation." } \\
\text { "I hope at the end of this course I can } \\
\text { also offer a course like this to benefit } \\
\text { my students." }\end{array}$ \\
\hline
\end{tabular}

*Note. (NB. These quotes were translated from Arabic into English by the researcher).

In addition, there are three social interaction tools provided by the Rwaq platform, which encourage communication, provide an opportunity for students to express their appreciation ("like" tools) and enable the sharing of website links, comments, questions, and responses to questions. The following are the three main sub-system functionalities:

1. The wall tool (negotiation page): publishing and sharing knowledge in posts, where students can write comments on each other's "statuses."

2. The messaging tool: participants send private messages to the teacher, which could facilitate and enhance student-teacher communication.

3. The Q\&A tool: asking and answering questions in discussions between participants in relation to the learning topics.

In addition, there was a lecture report, only available to the female teacher. This provided relevant statistics, such as the number of students viewing the video, the number of topics completed by the students - as opposed to the number of topics covered by the course overall - and the number of comments posted. Moreover, these data needed to be compared with the results of the End of Course Survey, in order to achieve a satisfactory level of reliability. As a result, the hypothesis on the participants' competence and the effectiveness of the course as a whole would be supported.

\section{The End of Course Survey}

A quantitative research design was adopted, namely a survey approach. This End of Course Survey was administered only to those students registered on the Rwaq course. The teacher used a Google Forms e-questionnaire to gather the participants' views on their experience of the course and their perceptions of its effect on their studies and lifestyle, as well as exploring their level of satisfaction. The questionnaire designed consisted of multiple choice questions on 5-point Likert scales: Strongly Disagree, Disagree, Undecided, Agree, Strongly Agree; and Very Dissatisfied, Dissatisfied, Neutral, Satisfied, and Very Satisfied. 
Questionnaire surveys are an ideal method of collecting information from a large number of participants, giving insights into the structure of the sample, as well as gathering data on their characteristics, views, and level of satisfaction. It is not easy to achieve this using other techniques (Salant \& Dillman, 1994). Despite all these advantages, however, this approach is prone to certain limitations; for instance, it may not deliver optimal results if an understanding of historical context is required. Moreover, the interaction between the students and their teacher will have a major impact on learners' satisfaction and the challenges they perceive as inhibiting them. This is because the clarity of the content and its organisation are also considered as the keys to successful learning. In fact, Fekula (2010) states that the teacher's role is very important for ensuring student satisfaction.

The End of Course Survey investigated student satisfaction with the course and the Avatar experience on the Rwaq platform, as well as the factors affecting this satisfaction, such as course design and content, motivation, teaching quality, learning style, positive perceptions of online learning, studentteacher and student-student interaction, and familiarity with technology. The e-questionnaire responses were then analysed using Microsoft Excel, which supports various chart formats; for example, pie charts and tables. These can be easier to read than a numerical table. Moreover, all the data were given as percentages. The following are some of the findings derived and an analysis of the online End of Course Survey with total of 830 responses.

Knowledge of Massive Online Open Courses (MOOCs). When the participants were asked about their knowledge of open educational platforms, $42 \%$ of them replied that they were already registered on a MOOC platform. Twenty percent stated that they had heard of them, but only $5 \%$ claimed to be MOOC experts (Figure 3).

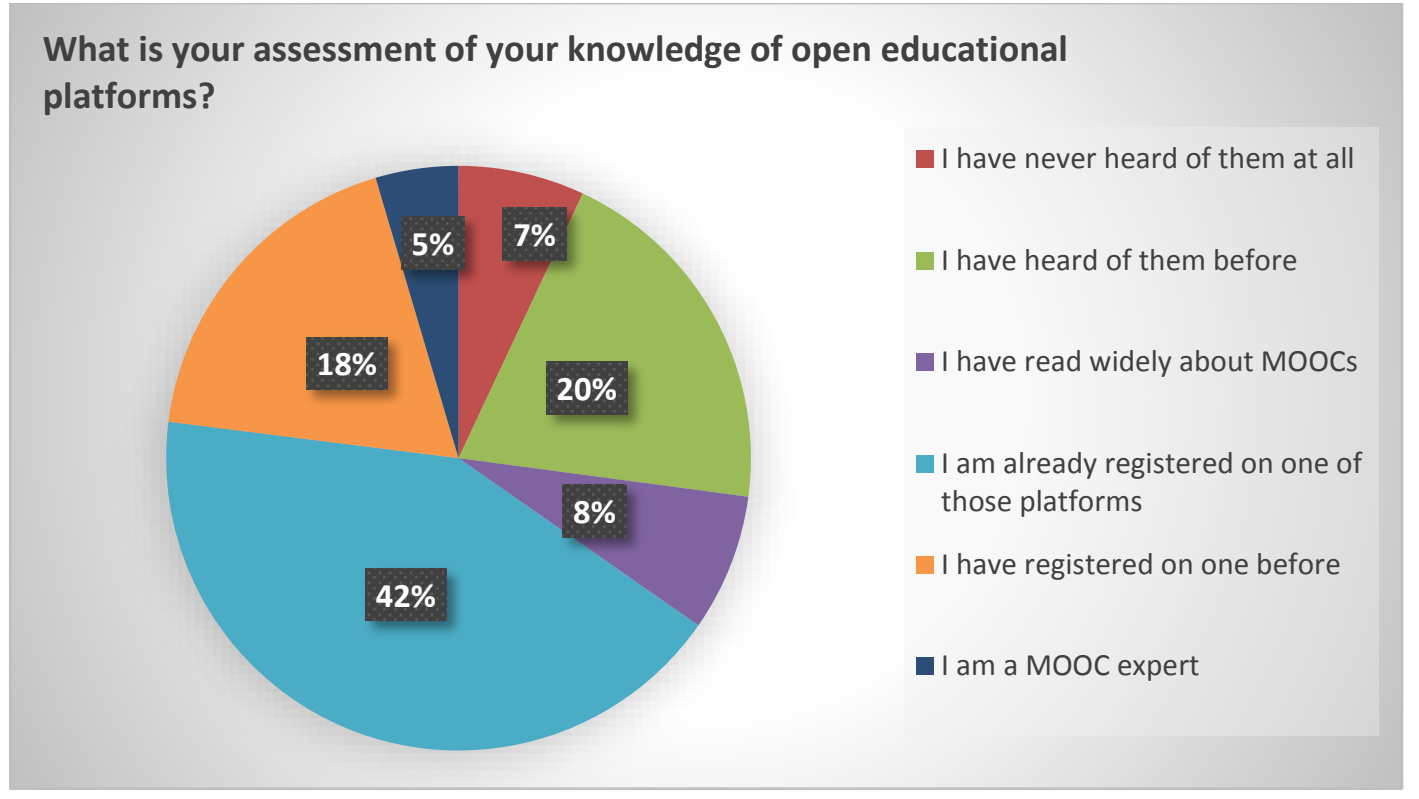

Figure 3. Percentages of students' responses concerning open educational platforms.

The course learning outcomes. For the questions about what the students had gained by completing the course, most of the respondents thought they had learned how to design a MOOC course. Around $18 \%$ found the online learning experience interesting and similarly, $18 \%$ declared that their learning skills had improved. Only $7 \%$ stated that they sought improved interaction with their teacher and peers (Figure 4). 


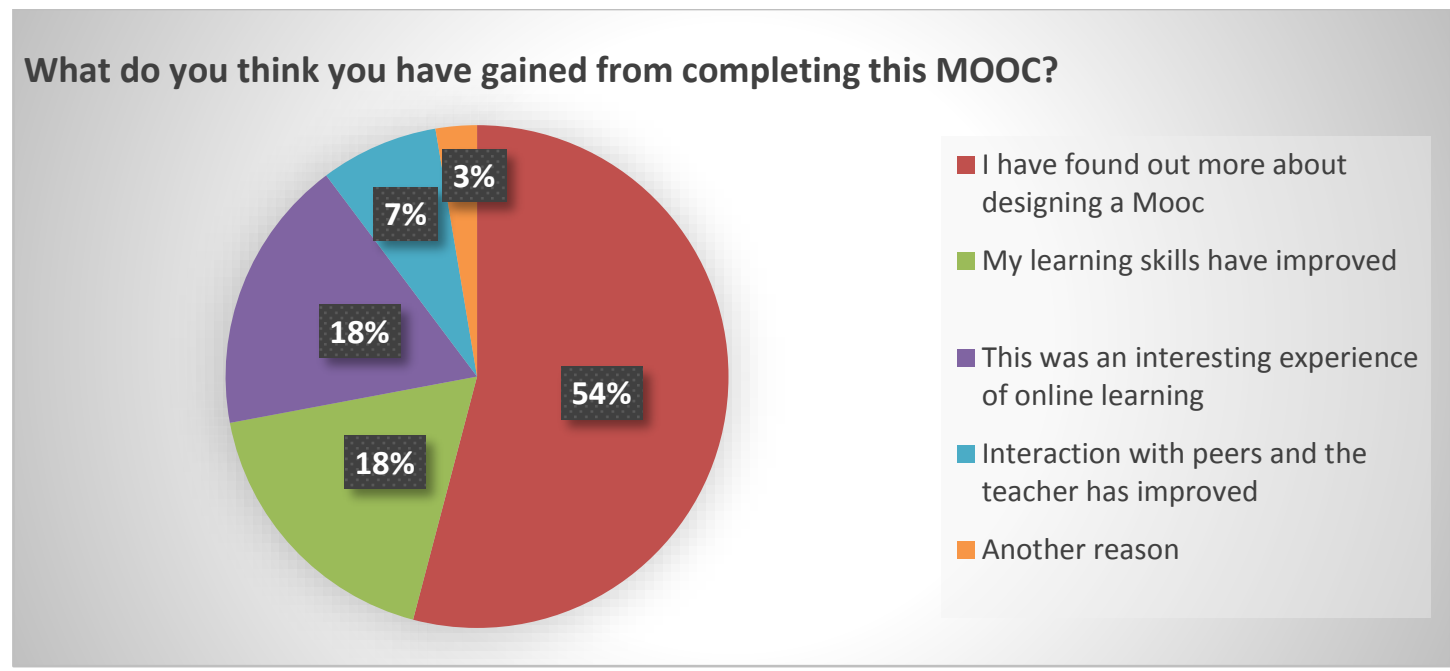

Figure 4. Percentages of students' responses concerning the MOOC learning outcomes.

Satisfaction with student-teacher interaction via Avatar technology. The question; how satisfied or dissatisfied were you with the interaction you achieved with the teacher using the Avatar instead of the video of the presenter herself? It is clear from Table 4 that almost half the students were "Satisfied" with the level of interaction achieved with their teacher using the Avatar tool and more than a third were "Very Satisfied." In contrast, just 13\% were "Neutral" and only $3 \%$ were "Dissatisfied."

Table 4

Percentages of Students' Responses Concerning Interaction With the Teacher

\begin{tabular}{|l|c|c|}
\hline Overall satisfaction with interaction with the teacher & Frequency & $\%$ \\
\hline Very dissatisfied & 0 & - \\
\hline Dissatisfied & 24 & $3 \%$ \\
\hline Neutral & 111 & $13 \%$ \\
\hline Satisfied & 406 & $49 \%$ \\
\hline Very satisfied & 289 & $35 \%$ \\
\hline Total responses & \multicolumn{2}{|c|}{830} \\
\hline
\end{tabular}

Learning style. As displayed in Figure 5, the majority of the students preferred watching the course videos, while around $13 \%$ were more interested in reading the comments made by their peers. However, only $3 \%$ preferred posting their own comments on the "wall." 
What aspect did you enjoy most while learning on this MOOC?

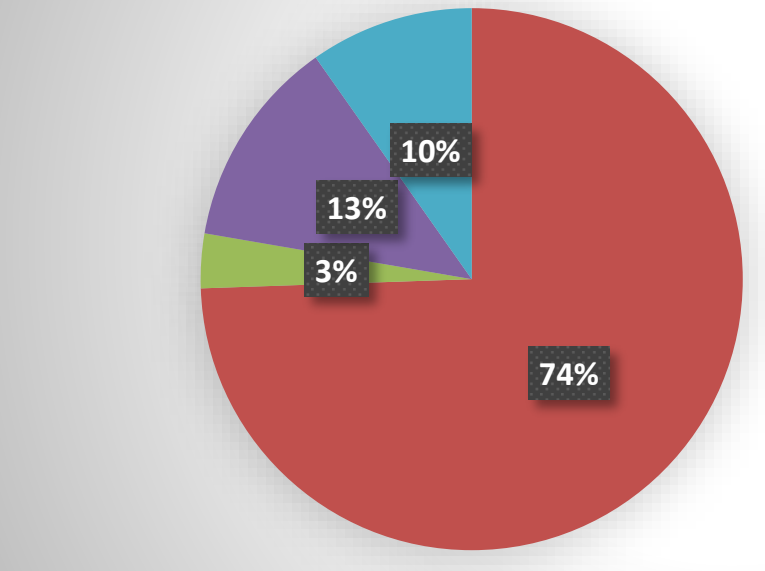

Watching the videos

Adding comments and ideas on the wall

Reading comments and discussion from other students

Other

Figure 5. Percentages of students' responses concerning their preferred learning styles.

The lecturer's appearance in the video-recordings. This last question concerned the appearance of the actual teacher in the MOOC material, whereby half the participants stated a preference for Avatar technology, rather than a video of the actual teacher; while approximately one third of the participants appeared to favour a video of the teacher herself, compared to the $19 \%$, who declared that they would rather see a PowerPoint presentation, with just a voiceover from the teacher (Figure 6).

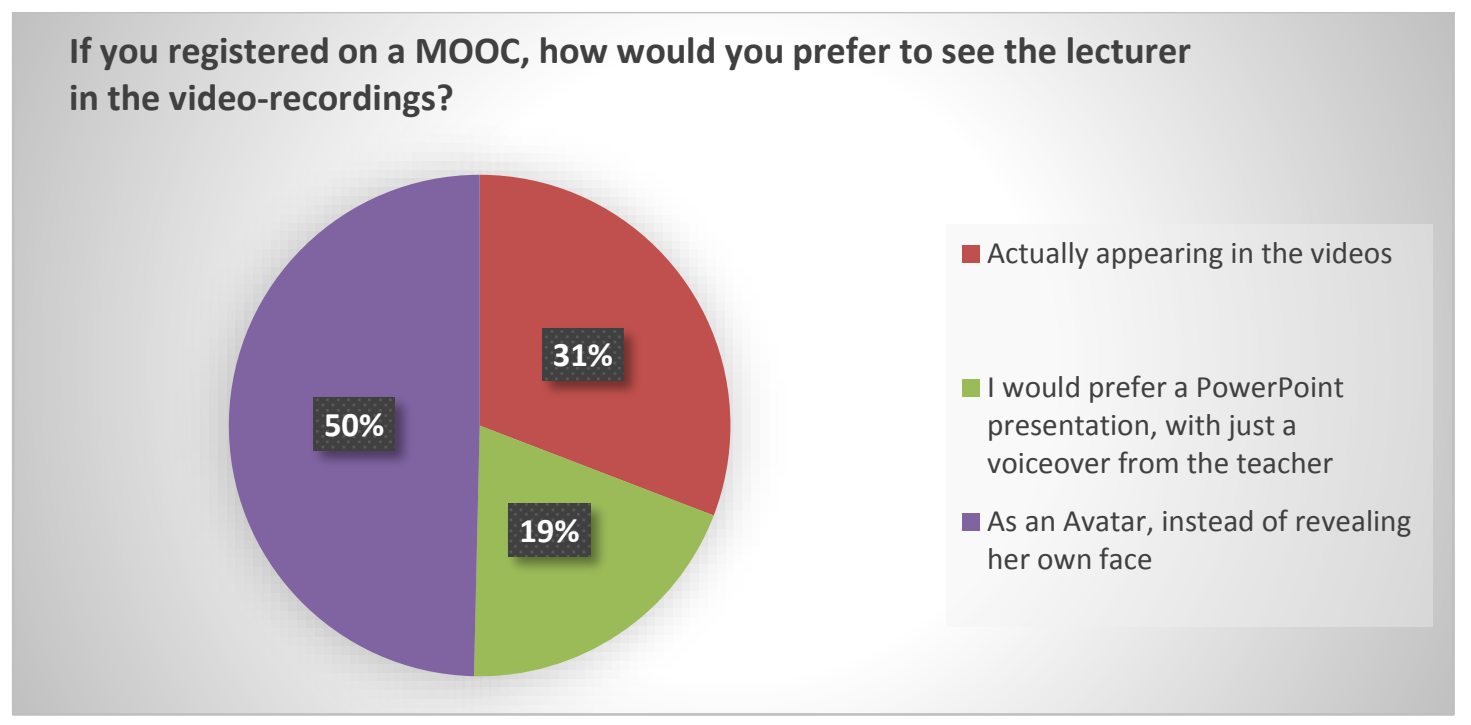

Figure 6. Percentages of students' responses to the lecturer's appearance in videos.

\section{Discussion}

This section discusses the study results, especially the characteristics of the qualitative data collection, in order to try and understand the social phenomena and quantitative data associated with the relationship between the effectiveness of the course and learner satisfaction. The study has been 
designed to capture the experience of online teaching, whereby a female teacher uses an Avatar tool, instead of appearing in person in video material. The participants' responses are therefore interpreted according to the context being investigated (Savin-Baden \& Major, 2013). The findings consequently indicate that the social presence of the student and teacher promote shared control over online learning. A good example of student-teacher interaction involved the latter answering the students' questions and responding to their comments. Besides, enhanced social interaction is likely to lead to greater effectiveness, efficiency, satisfaction, and engagement amongst students.

Alternatively, the findings from the participants' perceptions and feedback revealed that feedback was mainly positive regarding the course content and its organisation, videos, course materials, assessment, Avatar tool, and social interaction. Moreover, in the context of this study, an organisation's culture can be suggested as influencing participants' views on female teachers, which may be observed from the comments; for example: "The Avatar is considered as one of the available options for delivering an electronic lecture at the discretion of the female lecturer concerned." Therefore, engaging in discussion with participants will generate ideas and shed light on the phenomena under investigation. The reason for this is that perceptions gathered from participants serves to alleviate the social boundaries associated with female teachers on MOOC platforms. Furthermore, some Avatars are generated to influence participants' perceptions and the first impression expressed in the present feedback was "inspiration," whereby one of the female participants stated that she would, "teach a MOOC course using an attractive Avatar tool; thank you for inspiring me." Another participant indicated that this is a successful solution for online students: "I will use the Avatar in my future educational videos, because I think that the students will like the idea."

In the End of Course Survey, most of the participants stated that their primary purpose for registering on the course was to learn how to design a MOOC, followed by using a MOOC platform to improve their learning skills; enjoying an interesting online experience, and engaging in more effective interaction with their teacher and peers, thus indicating the social function of MOOC platforms. Other identified motives which the teacher extracted from the students' video comments included peer-discussion, the sharing of ideas and knowledge, obtaining updates on new topics and technology, and finding the Avatar presenter interesting.

Moreover, the majority of the students declared that they would register in another MOOC with an Avatar presenter, rather than one where the teacher is actually represented in person. This illustrates the specific cultural context of Arab societies, especially in Saudi Arabia. It was reflected in most the positive comments made by the participants concerning the videos, when their perceptions and feedback were analysed. Overall, the survey results and the participants' perceptions also showed that most of the participants were "very satisfied" with their social interaction when the teacher used an Avatar character, which answers the submitted research questions at the beginning of this paper.

\section{Limitations}

The following are some of the limitations and difficulties that were faced by the teacher/researcher throughout the course, including content and technical issues. Specific examples include that some of the participants requested a practical dimension to the course, rather than mere information and concepts related to MOOCs. Another issue arising concerned the nature of the assessment, with some of the participants seeking weekly tests, instead of a single final test. I explained that this was impossible within the time constraints of the course. Furthermore, technical problems arose over the deadline for submitting the final test, where I failed to manage the system's clock correctly; the deadline for the test 
was intended as midnight on September $8^{\text {th }}$, but the actual cut-off was at oo:oo, at the start of the day. This disappointed some of the participants and so I decided to extend the test deadline for one more day.

\section{Conclusion}

As there are often limitations and issues surrounding online learning via MOOCs in gender-segregated societies, such as in Saudi Arabia, this study has aimed to develop a socio-interactive environment for communication, by adopting Avatar technology to represent female lecturers. This serves to enhance their presence, as well as encouraging social interaction between male and female participants. The hypothesis is that the use of Avatar technology for MOOCs could increase the participation of female instructors and resolve the issues they may face in this regard.

This case study, therefore, examines the impact of a female Avatar applied to a MOOC. The usability and performance of Avatars is consequently concluded from feedback on course content, course organisation, and videos, as well as from formal assessment and a survey. In addition, the research methodology is clearly identified throughout the study, in an application of mixed data collection methods.

The qualitative data and End of Course Survey results, alongside the literature review, are subsequently triangulated to arrive at a final conclusion. This study experiments with a new MOOC teaching approach, whereby an Avatar tool is adopted to ascertain its perceived and measured effectiveness, as highlighted earlier, in order to reach a systematic conclusion.

Overall, it is believed that the research questions submitted at the beginning of this study have been effectively addressed and determined. One of the most important principles of online learning is that it should be an enjoyable experience. One way this can be achieved is by developing an Avatar that can engage learners. After analysing the findings from the present study, it was found that most of the students' feedback was in support of the Avatar experience. The number of positive responses was surprising, having expected more critical comments. The reasons for this positive response were based on the need for more female instructors on MOOCs, as well as a desire for more motivational learning approaches. In conclusion, the findings point to some important benefits of adopting Avatars on MOOCs. Avatars may therefore be considered as new tools for online learning platforms, both in Saudi Arabia and worldwide. 


\section{References}

Adham, R. \& Lundqvist, K. (2015). MOOCs as a method of distance education in the Arab world-A review paper. European Journal of Open, Distance and E-learning, 18(1), 123-138

Adham, R., Lundqvist, K. \& Parslow, P. (2016). The use of avatars in gender segregated online learning within MOOCs in Saudi Arabia. Global Learn, 2016, 86-93

Baki, R. (2004). Gender-segregated education in Saudi Arabia: Its impact on social norms and the Saudi labor market. Education Policy Analysis Archives, 12(28).

Braun, V., \& Clarke, V. (2006). Using thematic analysis in psychology. Qualitative Research in Psychology, 3, 77-101.

Christensen, C. M., Horn, M. B., \& Johnson, C. W. (2008). Disrupting class: How disruptive innovation will change the way the world learns. New York, NY: McGraw-Hill.

Creswell, J. W., \& Poth, C. N. (2017). Qualitative inquiry and research design: Choosing among five approaches. Sage.

Dede, C. (2004). Distributed-learning communities as a model for educating teachers. In Society for Information Technology \& Teacher Education International Conference (pp. 3-12). Association for the Advancement of Computing in Education (AACE).

Fabri, M., Elzouki, S. Y. A., \& Moore, D. (2007, July). Emotionally expressive avatars for chatting, learning and therapeutic intervention. In International Conference on Human-Computer Interaction (pp. 275-285). Springer, Berlin, Heidelberg.

Fekula, M. J. (2010). Perpetual enrollment online courses: Advantages, administration, and caveats. Online Journal of Distance Learning Administration, 13,(1).

Garland, D., \& Martin, B. N. (2005). Do gender and learning style play a role in how online courses should be designed. Journal of Interactive Online Learning, 2, 67-81.

González, M. A., Santos, B. S. N., Vargas, A. R., Martín-Gutiérrez, J., \& Orihuela, A. R. (2013). Virtual worlds. Opportunities and challenges in the 21st century. Procedia Computer Science, 25, 330-337.

Graham, C. R., Allen, S., \& Ure, D. (2005). Benefits and challenges of blended learning environments. In Encyclopedia of Information Science and Technology, (1 ${ }^{\text {st }}$ ed.; pp. 253-259). IGI Global.

Gulati, S. (2008). Technology-enhanced learning in developing nations: A review. The International Review of Research in Open and Distributed Learning, 9.

Hamalainen, R. (2008). Designing and evaluating collaboration in a virtual game environment for vocational learning. Computers \& Education, 5o, 98-109.

Hartmann, T., Fischer, M., \& Haymaker, J. (2009). Implementing information systems with project teams using ethnographic-action research. Advanced Engineering Informatics, 23, 57-67. 
Jamaludin, A., Ho, C. M. L., \& Chee, Y. S. (2007). Argument-based negotiation and conflict resolution through enactive role play in second life. Frontiers in Artificial Intelligence and Applications, 162, 561 .

Leckey, J., \& Neill, N. (2001). Quantifying quality: The importance of student feedback. Quality in Higher Education, 7, 19-32.

Liyanagunawardena, T. R., Adams, A. A., \& Williams, S. A. (2013). MOOCs: A systematic study of the published literature 2008-2012. The International Review of Research in Open and Distributed Learning, 14, 202-227.

Liyanagunawardena, T., Williams, S., \& Adams, A. (2013). The impact and reach of MOOCs: A developing countries' perspective. eLearning Papers, 33. Retrieved from centaur.reading.ac.uk/32452/1/In-depth 33 1.pdf

Messinger, P. R., Stroulia, E., Lyons, K., Bone, M., Niu, R. H., Smirnov, K., \& Perelgut, S. (2009). Virtual worlds-past, present, and future: New directions in social computing. Decision Support Systems, 47, 204-228.

Nowak, K. L., \& Rauh, C. (2005). The influence of the avatar on online perceptions of anthropomorphism, androgyny, credibility, homophily, and attraction. Journal of ComputerMediated Communication, 11, 153-178.

Oestreicher, K., Kuzma, J., \& Yen, D. (2010). Avatar supported learning in a virtual university. Worcester Journal of Learning and Teaching, (4), 1-8.

Onsman, A. (2011). It is better to light a candle than to ban the darkness: government led academic development in Saudi Arabian universities. Higher Education, 62, 519-532.

Rwaq (2015, October 10). Rwaq (Blog post). Retrieved from https://www.rwaq.org/articles

Salant, P., \& Dillman, D. (1994). How to conduct your own survey. Wiley.

Savin-Baden, M., \& Major, C. (2013). Qualitative research: The essential guide to research and practice. London: Routledge.

Stopher, P. (2012). Collecting, managing, and assessing data using sample surveys. Cambridge, UK: Cambridge University Press.

Subbian, V. (2013, March). Role of MOOCs in integrated STEM education: A learning perspective. In Integrated STEM Education Conference (ISEC), 2013 IEEE (pp. 1-4). IEEE.

Universities UK. (2013). Massive Open Online Course, Higher Education digital moments? Universities UK, London. Retrieved from http://www.universitiesuk.ac.uk/highereducation/Documents/2013/MassiveOpenOnlineCou rses.pdf

Yin, R. K. (2009). How to do better case studies. In L. Bickman \& D. Rog (Eds.), The SAGE handbook of applied social research methods (pp. 254-282). Thousand Oaks, California: SAGE. 
The Use of Avatars in Gender Segregated Online Learning Within MOOCs in Saudi Arabia - A Rwaq Case Study Adham, Parslow, Dimitriadi, and Lundqvist

\section{Athabasca}

University

(c) (i) 